\title{
Increasing Aid for Poverty Reduction: Rethinking the Policy Agenda
}

\section{Rehman Sobhan}

\section{The background to the debate}

This article addresses the nexus between aid and poverty reduction. It challenges the conventional wisdom that enhanced aid is central to poverty reduction. There is a rich literature reviewing the impact of aid on poverty. It is now generally accepted that unless aid flows are located within a policy framework which is locally designed and owned its impact on poverty reduction will be muted. Furthermore, ownership over policy must be backed by effective governance to enhance its impact on poverty reduction. This argument is not new. It originated in the critique of aid policies going back to the early 1980s with the move by the Bretton Woods Institutions (BWI) towards policy-based lending conditional on structural adjustment reforms (SAR) in the less developed countries (LDCs). It was then argued that externally driven reforms which ignored the socio-political context of the reform process would be unsustainable. It was not till the late 1990s that the World Bank and other donors recognised that without ownership and improved governance their capacity to influence reform had been minimal.

\section{The PRSP process}

The linkage between donor aid commitments and poverty reduction is being expressed through the current fashion of the Poverty Reduction Strategy Papers (PRSP). The PRSP process is the direct outcome of the rather belated discovery by the donors of the importance of policy ownership as well as the need to focus on poverty. The development agencies have now made the PRSP process into the touchstone for pledging aid to the LDCs. Even the International Monetary Fund (IMF) locates its loans to LDCs within what it terms as a Poverty Reduction Growth Facility (PRGF).

The international development community is using the PRSPs as a metric for their aid strategies and are looking to the PRSP as the policy instrument of choice to meet the Millennium Development Goals (MGDs). The international community is now committed to a significant increase in aid flows in order to support their attempts to realise the MDGs. This has opened up debate on the capacity of particular LDCs to absorb these flows. But if aid flows need to be married to the overarching goal of poverty reduction, then the underlying policy regime as well as the commitment and capacity of the LDC governments to implement these policies remains more relevant than the volume of flows or the issue of absorption.

\subsection{Changing trends in Bangladesh's aid dependence}

How far is Bangladesh in need of more aid to meet its commitments under the MDGs and to finance its PRSP? Bangladesh was once an aid-dependent country. It is now a trade-dependent country. The aid-Gross Domestic Product (GDP) ratio in Bangladesh has declined from around 10 per cent in the 1980s to below 2 per cent in 2003/04. In contrast, its trade-GDP ratio has risen from 21 per cent in 1986 to 40 per cent in 2003/04. This decline in aid dependence is captured in the decline in the aid/investment ratio from 33 per cent in 1990/91 to 13 per cent in 2000/01 and the aid/import ratio from 50 per cent to 15 per cent in the same period. This decline in aid dependence reflects a fall in aid disbursement from US\$1.7bn in 1990/91 to US $\$ 1$ bn in 2003/04. Part of this decline in disbursement reflects the corresponding fall in aid 
commitments. But there is also a significant decline in aid utilisation, which is manifested in the fact that the aid pipeline as of June 2004 contained US $\$ 6 \mathrm{bn}$. This bloated pipeline has persisted through the 1990s - the pipeline in 1990/91 carried around US\$6bn of unused aid. Most of the aid in the pipeline relates to project aid. Programme aid feeds directly into the budget and foreign exchange reserves and is more easily absorbed in the form of current public expenditures and imports. Such forms of budgetary support have not remained immune from the hazards of inappropriate as well as ineffective use of public expenditure.

\subsection{Can Bangladesh make use of increased funding?}

Even though aid flows have declined, Bangladesh obviously does not face an immediate problem of shortage of aid. Otherwise it would have drawn upon its unutilised aid and used this to finance a larger Annual Development Programme (ADP). In practice the ADP has remained under-fulfilled for three years and the ADP/GDP ratio has declined. Bangladesh would thus need to be making better use of its existing public development expenditure to stimulate expansion in its infrastructure and social development programmes, which could have been possible through more effective use of available aid.

In practice, most of the unused aid is available in relation to project aid. This reflects the numerous problems which beset the use of such aid including complex donor disbursement procedures as well as attached conditionalities, slow decision making by the Government of Bangladesh (GOB), bureaucratic delays and weak capacity to implement projects. Part of this delay has occurred as a result of conflicts over dividing the spoils derived from aid-related contracts.

Donors remain preoccupied with malfeasant use of their aid. Bangladesh's poor standing in the league tables of Transparency International has contributed to donors' attempts to over-regulate the use of their aid. As with all such conflicts of interest, the disbursement process slows aid use without necessarily reducing the tendency for malfeasant conduct. Under the circumstances, stepping up project aid to invest in the infrastructure or even the social sector would not yield significant gains in the short run.

Current donor policy in Bangladesh has, however, led to a downgrading of investment in infrastructure projects in such areas as power, telecommunications, ports and energy development. This has, in part, originated in the poor governance associated with some projects manifested in slow implementation, misuse of funds, poor management, low efficiency and poor maintenance. Some donors such as the World Bank and some bilateral donors have advised the GOB to seek private sector investment to develop its infrastructure, but this has not been forthcoming, readily or to the extent that is needed. The end product of this de-emphasis has been a deceleration in much needed infrastructure capacity development which has impacted on the productive sectors of the economy and has inhibited private investment.

The donors have stepped up aid to the social sector, especially to health and education. However, here again major investments in these sectors have reflected a slow draw-down of funds due to many of the same problems which have constrained the use of aid funds in the infrastructure sectors. In the health sector, a consortium of donors committed a substantial volume of funds as part of an integrated programme for the health and population sector. However, the aid was tied to a major reform project in these sectors which was weakly implemented. The programme was then suspended by the GOB following a change of regime after the parliamentary elections of 2001. This contributed to low utilisation of funds in sectors which would have had a significant impact on human development.

Notwithstanding Bangladesh's poor utilisation of aid funds and associated governance problems in the education and health sectors, its record in meeting MDG goals in these sectors has been widely appreciated. Its school enrolment rates have improved with gender parity being realised at both the primary and secondary school levels, its infant and maternal mortality rates have declined, its contraceptive prevalence rate has risen from below 10 per cent to over 50 per cent in the last 25 years whereby its total fertility rate has halved, as has its population growth rate.

These positive developments in Bangladesh's social sector have been registered in spite of massive governance problems which afflict both the education and health sectors, which are manifest in the poor and possibly deteriorating quality of service delivery. Aid may have contributed in some 
measure to these positive human development outcomes, but since its impact is filtered through the system of governance, there are other variables which have been insufficiently captured in the analysis, which account for the improved performance. The positive role of Bangladesh's large and globally recognised NGO community may be one such factor, but this is hardly the main explanatory variable.

Bangladesh's record in poverty reduction has been positive but far from brilliant. Reduction of poverty from around 59 per cent in 1991/92 to 50 per cent in 2000/01 ranks as a moderate performance, but still leaves large numbers of people in poverty and has to take account of the increase in income inequalities in this same period. Here again no clear explanation is at hand to account for this poverty reduction. Weak correlations of poverty reduction with GDP growth trends, agricultural growth and the expansion of micro-credit do not provide an explanation which would withstand rigorous professional scrutiny or indeed provide guidance to policy makers seeking to craft a poverty reduction strategy for Bangladesh.

In such circumstances, it is difficult to come up with a categorical response as to whether Bangladesh could absorb a significant expansion in aid or would be able to use this accretion of resources very effectively. A more meaningful answer to this question of providing increased aid would thus need to be addressed in relation to the overall development strategy of the GOB and its capacity for improving governance.

\section{Bangladesh's PRSP process}

The interim Poverty Reduction Strategy Paper (PRSP) recently completed by the GOB may provide some guidance in answering these questions. This section of the article addresses the PRSP process both in the Bangladesh context and in more general terms and attempts to relate this discussion to the question of aid criteria for distributing resources across the LDCs. The concluding part of the article addresses the broader question of a more socially relevant agenda for poverty reduction and its relevance for rethinking aid strategies.

Bangladesh's PRSP is really a substitute for a medium-term development plan rather than a coherent strategy for poverty reduction. In fact it has no underlying macro-model which relates its programmes to specific time-bound, poverty- reducing outcomes. This is the problem with many other PRSPs across the world. Most of them, even those which demonstrate a largely indigenous effort, have felt compelled to incorporate the macroeconomic model originating from an earlier generation of structural adjustment reforms imposed by the BWI. The BWI's central goal is to accelerate growth. Poverty reduction is seen as a derivative of higher growth in this model. In practice the BWI growth model is itself loosely structured and its SAR policy correlates do not necessarily assure growth. Most finance ministers from subSaharan Africa and indeed Bangladesh would testify to my argument.

The recently completed draft of the Bangladesh PRSP, which is a largely indigenous effort, is a reasonably competent exercise. However, the GOB has felt compelled to genuflect to the SAR agenda even though its relationship to poverty reduction is at best tenuous. I provide a sample of the policy interventions culled from the Bangladesh PRSP to sustain this argument:

- Maintain fiscal discipline

- Enhance efficient use of resources

- Improve monetary management by the Bangladesh Bank

- Develop a domestic bond market

- Restructure nationalised commercial banks (this includes privatisation)

- Reform state-owned enterprises (this includes privatisation)

- Liberalise imports

- Create an enabling policy environment for the private sector

- Unbundle the power sector

- Open avenues for private sector participation in the railway sector.

All these strategies built into the PRSP incorporate a generation of reforms which originated in the Country Assistance Strategy (CAS) papers of the World Bank and the stabilisation programmes of the IMF over the last decade. While we may debate the celerity of the World Bank's import liberalisation strategy or its indiscriminate approach to privatisation, many of the reforms proposed in their CAS papers are sensible and desirable for reforming the Bangladesh economy. However, what is relevant to our argument is the fact that many of the policy reforms incorporated in the PRSP derived 
less from the felt needs of the $\mathrm{GOB}$ or the paramount concerns of the people of Bangladesh than from the CAS papers of the World Bank and a shelf load of "grey cover" reports prepared by the Bank for reforming the Bangladesh economy.

Nor is it clear how this reaffirmation of an ongoing donor-derived reform strategy furthers the goals of poverty reduction or indeed reflects the outcome of consultations with citizens and especially the poor. What little I know about the PRSP process in some other South Asian countries and indeed other LDCs around the world, suggests that the universal approach to reform associated with the SAR has found a place in the PRSPs of countries as disparate as Nepal, Uganda, Cambodia and Bolivia. While reforms in all these countries remain necessary, the point at issue is the ownership of these reforms and whether they add up to a coherent agenda for poverty reduction.

\section{The governance of aid use}

It is arguable that meeting many of Bangladesh's MDG targets today depends less on aid and more on the commitment of the GOB in the form of a reprioritisation of existing public expenditure and on improved governance. The gross enrolment ratio for primary schools in Bangladesh is now close to 100 per cent but the net enrolment ratio is closer to 70 per cent. Retaining children in school is not just a matter of resources but depends heavily on the quality of governance of the schooling system. This relates to the capacity to discipline teachers to take classes, increase contact hours with students and improve the curricula and teaching methods. If such improvements in governance were to take place, then physical investments to upgrade the quality of school buildings and facilities, provide better teaching materials and even meet nutritional MDG goals by providing school meals for children, would benefit more fully from enhanced inflows of aid to Bangladesh.

Bangladesh's PRSP estimates that the cost of providing a minimally nutritious lunch to 13.5 million school age children ( 80 per cent of the target population) would come to about US $\$ 245 \mathrm{~m}$ a year. This amounts to around 5 per cent of the total revenue budget of about US\$5bn of the GOB for the fiscal year 2004/05 and 24 per cent of the US $\$ 1$ bn of aid disbursed in 2003/04. The total cost of a programme to provide comprehensive sanitation to the rural areas of Bangladesh is projected to cost US $\$ 25 \mathrm{~m}$ in 2005 rising to US $\$ 35 \mathrm{~m}$ in 2015, which is the target year for covering the entire rural population of 68 million. It will cost another US\$18m to meet the sanitation needs of an urban population of 37 million in 2015. These again are not large sums of money either for the $\mathrm{GOB}$ or the donor community.

In both cases - school meals and sanitation the sums involved for the GOB remain manageable. However, the operative issue will be for Bangladesh's aid donors to enhance their aid commitment to accommodate these and other programmes which can make an impact on poverty and are identified with the MDGs. Given the current levels of aid disbursement, this would require a sizeable increase in aid commitment to Bangladesh to accommodate some of these poverty reduction programmes. However, Bangladesh's aid utilisation remains poor and the current aid pipeline still carries US $\$ 6 \mathrm{bn}$ in unspent aid. The problem faced by the GOB is therefore to not just attract more aid but to utilise it both promptly and effectively.

If the GOB aspires to attract more aid to meet the MDGs, it will need to demonstrate that it has, for example, put in place a credible, well-supervised programme which sees that schools across the country are equipped to provide a nutritious meal to schoolchildren without leakage of funds or diversion of food at the cost of serving inadequate meals to the children. This would involve both enforcing transparent systems of oversight by the government and the public over the programme, and establishing the accountability of the school authorities to the local community, including the parents and the children themselves.

All such governance-related issues are duly recognised in Bangladesh's PRSP, as in those of many other LDCs. However, there is a wide gap between registering fealty to good governance on paper and introducing this into the actual practice of governance. Bangladesh, as indeed most LDCs, is not misgoverned out of ignorance of the latest advances in the development discourse. There is an underlying political economy which provides the dynamic to a country's governance. There is no evidence that this political economy has undergone a sea change in the post-MDG/good governance era. Nor is the aid provided by donors really enough to persuade those who benefit from malgovernance in the country to change their ways. Indeed the present tendency of aid donors, led by the BWI, to preach 
good governance to recalcitrant LDC regimes lacks credibility because they are rarely backed with a sufficiency of carrots or a strong enough stick. In Bangladesh, where current aid disbursement accounts for less than 2 per cent of GDP, donors have little capacity to leverage change unless the GOB is a willing and effective partner to such change.

\section{Incoherence in donor policies}

The tendency by donors to dwell on the malgovernance of the state while praising Bangladesh's macroeconomic fundamentals is not a sound recipe for inducing better governance. At a recent conference in Paris on 'Joint Progress towards Enhanced Aid Effectiveness', the Bangladesh Finance Minister suggested that aid flows should be guided by results rather than conditions. This also seems to be the view of the British government, which was articulated by $\mathrm{Mr}$ Hillary Benn at the same conference in Paris. This suggests that we may be witnessing yet another change in aid strategy, at least among some donors.

However, it is not clear if donors are still agreed on the yardstick to evaluate good results which may guide their aid priorities. There are several sets of success indicators guiding donor policy today. These include realising the MDGs, sustaining "satisfactory" growth rates, and meeting rather more vaguely defined goals of good governance. While the MDG goals are inspired by the recent commitment to poverty reduction and improved human development, the growth indicators are a legacy of the SAR era. These SAR indicators demand that particular countries also attain macroeconomic stability, liberalise their imports and privatise their economies. The IMF makes the achievement of such SAR goals conditional for accessing loans under their PRGF. A policy regime, which was once viewed as a means to enhance growth, has now acquired a life of its own and has also become an end in itself, both for the BWI as well as for some bilateral donors.

The third set of goals relating to good governance remains much more nebulous. They include democracy, human rights, the rule of law, ending corruption and greater transparency and accountability in governance. Donors prefer to talk about such goals but still tend to view them as instrumental for promoting reforms rather than as ends in themselves which will merit reward and punishment for performance success or failure.
The problem with this multiplicity of goals and indicators of good performance lies in the confusion in the conceptual premise underlying these goals. There is an assumption that high growth can only be realised through faithful implementation of SAR derived from the Washington Consensus. Thus higher growth is assumed to lead to poverty reduction, so SAR is itself seen as essential to poverty reduction. This argument informed the World Development Report of 1990, but seems alive and well in 2005 and underlies the PRSP of virtually every LDC across three continents. This reform-poverty nexus has now been married to the proposition that good governance, including democracy, reduced corruption etc., will promote effective reforms, enhance growth and reduce poverty. However, this multi-dimension perspective provides a poor basis for driving aid strategy.

Bangladesh's governance is recognised by donors to be poor, and this has been articulated with increasing stridency at recent meetings of the Bangladesh Development Forum (BDF). However, by LDC standards, Bangladesh's record on attaining MDGs goals, growth, poverty reduction and macroeconomic stability is quite good - hence the emphasis by its Finance Minister on the need for using outcome indicators. Vietnam's record in growth, poverty reduction and MDG indicators is perhaps one of the best in the world. However, in indicators of SAR, or good governance defined by human rights, democracy, transparency and accountability, Vietnam would rate below Bangladesh and indeed many LDCs.

So what conclusions do we draw about relevant indicators to guide aid flows? Should aid donors demand an improvement in law enforcement in Bangladesh or a plural political system and free elections in Vietnam before they enhance aid? Or should donors move away from setting policy guidelines and simply focus on the issue of aid absorption, where again Vietnam would score very highly. Indeed it is arguable that both the enhanced use of conditionalities, including good governance, and confusion over performance indicators may be inimical to the efficacy of aid absorption. It is not surprising that many LDC governments, including Bangladesh, argue that the best way to enhance aid absorption is to offer it in the form of budgetary support which should be provided on the basis of a limited set of performance indicators associated with growth and the realisation of MDG goals. But 
the MDG goals are many and complex. Without establishing priorities and weighting these goals, it is far from clear that the MDGs can provide a meaningful guideline for aid commitment. Nor is it clear that donors are willing to trade off 5 per cent growth as well as good progress in some human development indicators with tolerance for autocratic governance, weak rule of law, endemic corruption and rampant crime.

The tensions in donor thinking derive from their weak understanding of the dynamics of poverty reduction and its relationship to growth as well as governance. It is acceptable for academic economists to run regressions to demonstrate that high growth rates can be correlated to reduced poverty. While this empirical evidence may be debated in seminars, it is hardly adequate to guide a Finance Minister towards liberalising imports or privatising banks and water supplies in the expectation that this will result in high growth and hence poverty reduction. Nor is it adequate to cite the works of political scientists providing positive links between their pet measures of good governance with poverty reduction driven by fidelity to SAR.

A working Finance Minister needs evidence of a much more robust chain of causality between a regime of well-governed policy reforms, with growth and poverty reduction. In a meaningful PRSP, the relevant indicator should be poverty reduction where growth would serve as an instrumental indicator. Such a move to prioritise poverty reduction would need a fuller understanding of the dynamics of poverty. It is argued here that poverty originates in the structural injustices of a society. But there is little recognition of the structural dimensions of poverty or the evidence of policy interventions in the PRSPs to correct the injustices which constrain the opportunities of the poor.

\section{Conclusions}

\subsection{Redesigning the PRSP to correct injustice}

The PRSP process needs to address the structural dimensions of poverty if it aspires to not just reduce but to eradicate poverty. The relevant indicators of injustice which demand redress include the following:

- the lack of access of the poor to productive assets

- the terms on which the poor participate in the market economy
- the disparity in the quality of education and health care available to the poor compared to the elite

- the inequitable quality of governance in a society.

\section{Strategies to eradicate poverty}

Such a redirection of the PRSPs as well as aid strategy would need to address the issue of correcting injustice through the empowerment of the poor, by strengthening their capacity to participate in a market economy and a democratic polity. The proposed policy interventions may be structured under the following heads:

- expanding the ownership and control of the poor over productive assets including corporate assets

- enhancing access of the poor to a knowledgebased society by upgrading the quality of public education

- providing quality health care to the poor

- strengthening the capacity of the poor to compete in the marketplace and to move up the value addition chain

- redesigning budgetary policy to reach public resources to the poor

- restructuring monetary policy to deliver credit and provide savings instruments to the poor as well as to acquire corporate assets

- designing institutions to enable the poor to participate more productively in a market economy

- enhancing the capacity of the poor to make their rightful claim on the services of the state

- empowering the poor to participate more fully in the democratic process

- restructuring international institutions to prioritise the concerns of the poor.

\section{Rethinking aid strategies}

Such a redirection in the strategy for poverty alleviation remains part of a political process which must originate from a deeply indigenous process of policy debate and public action. Donors can assist this process, but they cannot substitute for it. Significantly enhancing aid flows to target the most basic deprivations of the poor remains an important commitment of the international community. However, the critical issue beyond providing mosquito nets and subsidised fertiliser for the poor is to enhance their capacity to buy these essential 
needs from income generated by their participation in the development process. This will require a change not just in the level but in the perspectives of aid policy. This willingness to rethink aid strategies will indicate whether poverty eradication derives from a sincere commitment of the international community to strike at the sources of the injustice which perpetuate poverty, or whether aid is being provided to merely alleviate its symptoms. Significantly expanding aid flows to the LDCs and seeking improvements in their capacity to absorb aid should, in this context, be seen as part of a transitional process. The effective utilisation of enhanced aid flows to the LDCs must, in the final analysis, be directed to support the capacity of the poor to challenge the injustices of a social and global order which has condemned them to live on the margins of society. 